\title{
Visualization of flow phenomena in hydraulic throttle valves of plastics
}

\author{
Michał Banaś ${ }^{1, *}$, Piotr Antoniak ${ }^{1}$, Lubomir Marciniak ${ }^{1}$, and Jarosław Stryczek ${ }^{1}$ \\ ${ }^{1}$ Fluid Power Research Group, Wroclaw University of Science and Technology, 50-370 Wrocław, \\ Poland
}

\begin{abstract}
Using elements made of plastics in hydraulic drives and controls encounters problems, for example related to strength. However, the advantage of solutions with plastics manifests itself, among others in possibility of shaping hydraulic elements in accordance with the assumed requirements. The use of additive manufacturing techniques allows us to make plastic parts with shapes that are unattainable for steel parts. The authors have attempted to determine the influence of the shape of the closing element on the phenomena of flow through the throttling gap in the hydraulic throttle valve. They chose three poppets of different shapes and carried out flow simulations using CFD. They compared simulation results in the form of flow velocity field in the valve chamber with observations obtained with the Particle Image Velocimetry (PIV) technique. In visualization tests, a throttle valve made of transparent materials and markers in a form of air bubbles were used. The tests confirmed the possibility of using air bubbles as markers of the PIV method at low pressure. The presented conclusions indicate the need for further modification of the shape of the closing element as well as of the design of the valve body.
\end{abstract}

\section{Introduction}

Parts made of plastics have been used in many branches of mechanical engineering. Application in hydraulic drives and controls is limited. However, researches have been trying to build plastic components [1], like gear sets to pump hydraulic [2] and their bodies [3], valves [4], cylinders as well [5].

Plastics have many advantages for hydraulics. Due to the lower density of the material components have lower mass, which is an advantage in control of valves [6] and pumps [7]. Noise reduction is also important [8]. Another area of application is in the hydraulic circuit with water or special liquids like magnetorheological [9]. Components for water hydraulics are currently made of stainless steel [10] or special coatings for carbon steel are applied [11]. Moreover, for plastic components we can use additive manufacture methods, which facilitate complex shapes $[12,13,14]$ and they are used in less loaded parts of centrifugal pumps [15]. Lower strength and larger deformation [16] and also the state of the surface of

\footnotetext{
*Corresponding author: michal.banas@pwr.edu.pl
} 
elements made of alternative methods like fused deposition modeling (FDM) [17], limit the use of plastics in hydraulics.

CFD method is commonly used to analyze the flow phenomena in the different hydraulic components. Less recognized cases require verification of assumptions and simplifications. One way to verify them is to observe the flow phenomena with particle image velocimetry (PIV) technique, which is used for the 3D flow, but also to 2D [18, 19]. Many measurement systems use special markers and lighting kits [20, 21], but they can be simplified if we track moving air bubbles [22].

The velocity and pressure distribution in valves with various shapes of closing element is different due to the flow of fluid through chambers and gaps in the valve. This changes the characteristics of the valve as well. Design of plastic valves needs verified numerical model that can be used in the CFD method.

The authors developed a valve model with number of different poppet and conducted simulation of fluid flow. We used the PIV method with air bubbles to identify the flow velocity within the valve. We compared the results of numerical calculations with experimental studies. For the experimental prototype we used a throttle valve made from a transparent plastic.

\section{The throttle valve}

\subsection{Test object}

In the experimental tests a throttle valve made from plastic has been used. Fig. 1a shows a simplified cross-sectional view with some important dimensions. The valve body is made of poly(methyl methacrylate) (PMMA) which is transparent and allows observation of the phenomena inside the valve.

An adjusting screw (2) moves axially closing element (3) relative to the socket (4) to form a throttle gap with a variable section. Fluid enters the valve through the IN channel and then through the throttle gap gets into the body chamber (1) and out of the valve through channel (OUT).

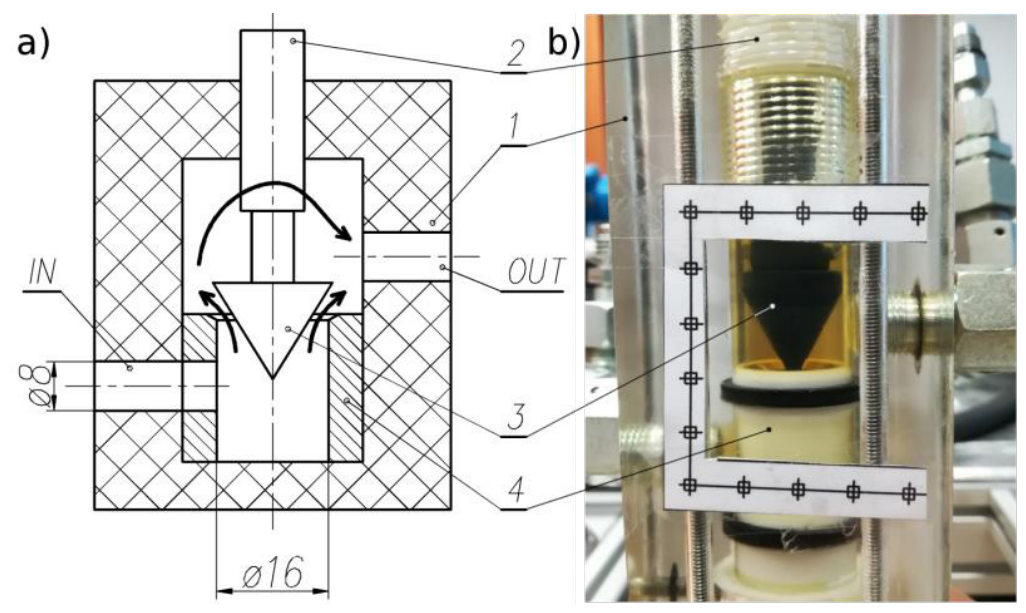

Fig. 1. Tested valve; a) a section of the valve; b) a view of the valve; 1 - body, 2 - setting screw, 3 - poppet, 4 - seat 
We selected for tests three poppets shown in Fig. 2. Cone (a) has the shape typical of the design used in the hydraulic systems with an opening angle of $30^{\circ}$. Solution (b) corresponds to a pair of ball-seat which is used in seat valves from steel. An example of the implementation of the FMD is closing element (c), whose shape can be changed in a different way.

The characteristics of the valve also affects the shape of the seat (Fig. 1). The industrial solutions used chamfered or sharp edge. In the test valve we used chamfered one (Fig. 1) due to the cooperation with the cone made of polylactic acid (PLA). PLA is a popular material designed for 3D printing (e.g. FDM) but its hardness is not sufficient enough to work with sharp edges.

a)

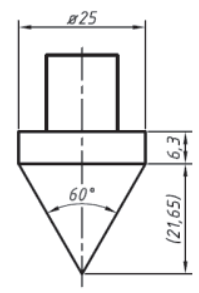

b)

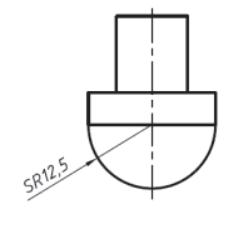

c)

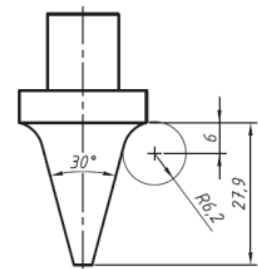

Fig. 2. Shapes of the tested poppets: a) cone, b) half-ball, c) cone with roundness

\subsection{Numerical research}

A simplified geometry of the valve was modeled in ANSYS ${ }^{\circ}$ R17.2, omitting many details, such as chamfers and fillets that have no significant effect on the velocity distribution. Input and output are replaced with unthreaded holes in the body wall with a flow diameter of the fittings. Input and output channels have been added, to stabilize the nature of the fluid flow.

Space occupied by the fluid was isolated from so prepared valve. For a given distance of the valve poppet we carried out discretization of fluid volume into the finite elements using various types of mesh. In the auxiliary areas (e.g. the input and output channels) and in the channels which do not play a significant role in the flow of fluid we applied structured grid with lower density. The refined mesh has been used in the gap between the cone and the seat and around the closing element. Total amount of elements is approx. 800,000 items of different types, including tet4, hex 8 , wed6, pyr5.

The hydraulic oil used for the simulation HLP68 was defined independently (density $\rho=780 \mathrm{~kg} / \mathrm{m}^{3}$, dynamic viscosity $\mu=0,095 \mathrm{~Pa} \cdot \mathrm{s}$ at $T=30{ }^{\circ} \mathrm{C}$ ). Constant temperature, no heat transfer, turbulence model SST and no-slip wall were assumed in simulations.

The boundary conditions in a form of constant velocity in the auxiliary input channel resulting from a predetermined flow rate $(v=Q / A)$ and pressure in the output channel $p_{2}=0 \mathrm{MPa}$ has been taken.

\subsection{Experimental studies}

In experimental studies the hydraulic system shown in Fig. 3a has been used. The test valve (1) was supplied by the hydraulic pump (2) from the tank (3). Operating parameters, i.e. the flow rate $Q$ and the input $p_{1}$ and the output pressure $p_{2}$ were controlled with the flow control valve (4) and the pressure relief valve (5). Transducers for pressure (6) $\left(p_{\max }=2.5 \mathrm{MPa} ; 0.5 \%\right)$ and $(7)\left(p_{\max }=10 \mathrm{MPa} ; 0.5 \%\right)$, flow $(8)\left(Q_{\max }=16 \mathrm{dm}^{3} / \mathrm{min} ; 0.3 \%\right)$ and temperature (9) $\left(T_{\max }=125^{\circ} \mathrm{C} ; 2 \%\right)$ were used in the measurements. In parentheses we 
showed the range and accuracy of transducers. A view of the valve on the test is shown in Fig. 3b.

We took measurements for all closing elements at steady-state flow. Turning of the adjusting screw (pos. 2, Fig. 1) changed the position of the poppet (pos. 3, Fig. 1) which was measured as a distance between the frontal face of the screw and the valve body to achieve the desired parameters (flow rate $Q=1,3,10( \pm 0.5) \mathrm{dm}^{3} / \mathrm{min}$, temperature $T=40( \pm 5)^{\circ} \mathrm{C}$, the poppet displacement $h=1,3,12( \pm 0.1) \mathrm{mm}$, frequency $f=2000,1000$, $500 \mathrm{~Hz}$ ). The air bubbles were introduced into the circuit by short opening of the shut-off valve (10). Once the flow was stabilized and the number of air bubbles in the chamber of the valve body was reduced, the camera (12) started image recording. Recording was performed at a frequency $f$ depending on the flow rate $Q$ and the resolution of $600 \times 800$ points and exposure time of $400 \mu$ s aperture f/2.8. Flow was recorded for approx. $2 \mathrm{~s}$.

a)

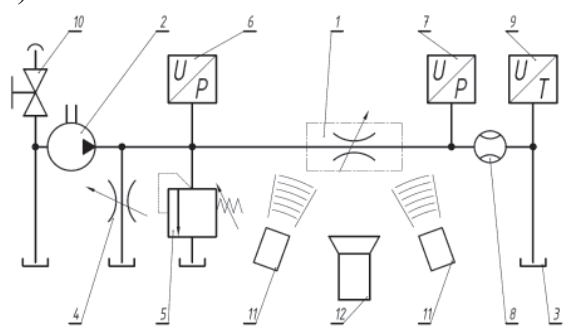

b)

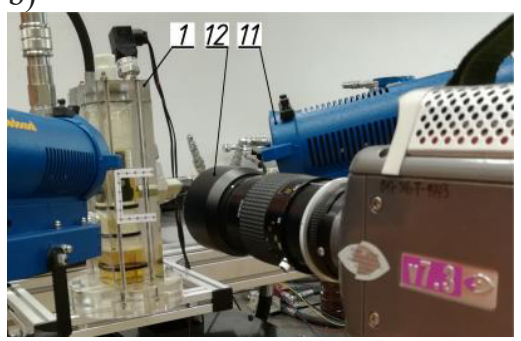

Fig. 3. Test stand: a) hydraulic circuit; b) the valve on the test stand; 1 - tested valve, 2 - hydraulic pump, 3 - tank, 4 - flow control valve, 5 - pressure valve, 6,7 - pressure transducers, 8 - flow transducer, 9 - temperature transducer, 10 - shut-off valve, 11 - lights, 12 - high-speed camera

Recorded material has been processed digitally to enhance the visibility of air bubbles in the fluid by increasing the brightness, contrast, and using the sharpen filter. Using the frame-by-frame observations we determined manually positions of the selected markers to form a set of streamlines (Fig. 4c). Calculating average resultant velocity in the XY plane for the entire area we determined the velocity field presented in the form of a contour plot in Fig. 4d.

\section{Analysis of the results}

The streamlines indicate the uniform flow of oil around the closing element (Fig. 4a). We can see the flow in the plane of symmetry of the valve, as well as the flow in front of that plane. At the top of the poppet cone by exiting the seat clear turbulences have been formed and they move right into the space between the outlet from the seat and the inlet to the output channel. Shape of the lines there is most irregular.

During the experimental studies (Fig. 4c) the shape of the selected streamlines is similar to the results of simulation. Lines in the outlet from the seat are more upright with fewer curves admittedly, but this is due to the registration by the camera motion of markers only in the XY plane and skipping $z$-component of the velocity.

Browsing the velocity field obtained by simulation we notice three chambers, where there is a limited motion of the fluid $(v \cong 0 \mathrm{~m} / \mathrm{s})$. There are the space above the closing element as well as the left and right corner of the main chamber in the plane of crosssection. Velocity of the liquid flowing from the throttle gap is greater on the right side $\left(v_{\max 1}=4,7 \mathrm{~m} / \mathrm{s}\right)$ where there is a short distance to the output channel. On the left side fluid needs to circumnavigate the poppet and therefore the speed is lower $\left(v_{\max 2}=2,7 \mathrm{~m} / \mathrm{s}\right)$. The maximum velocity of the fluid in the output channel $\left(v_{\max 3}=5,4 \mathrm{~m} / \mathrm{s}\right)$ is higher, which 
results from the unequal flow through the throttling gap and partially masked the output channel with the cylindrical surface of the poppet. We observe it in a form of increasing flow rate from the chamber above the poppet.

Velocity field obtained in the experimental tests (Fig. 4d) is qualitatively similar to the results of CFD analysis. We observe non-central and unsymmetrical flow through the throttle gap. This is mainly due to inaccuracy of poppet manufacturing with the FDM technique and precision of the $3 \mathrm{D}$ printer. The absolute values are different, which is also related to the unsymmetrical arrangement of the poppet in the seat. Another reason is the missing z-component of the speed and thus the resultant value is underestimated. The velocity at the inlet to the output channel $\left(v_{\max 2}=4,7 \mathrm{~m} / \mathrm{s}\right)$, where the dimension in the $\mathrm{Z}$ direction is of less importance (the diameter of the hole is smaller than the outer diameter of the poppet) is closer to the calculated by CFD.

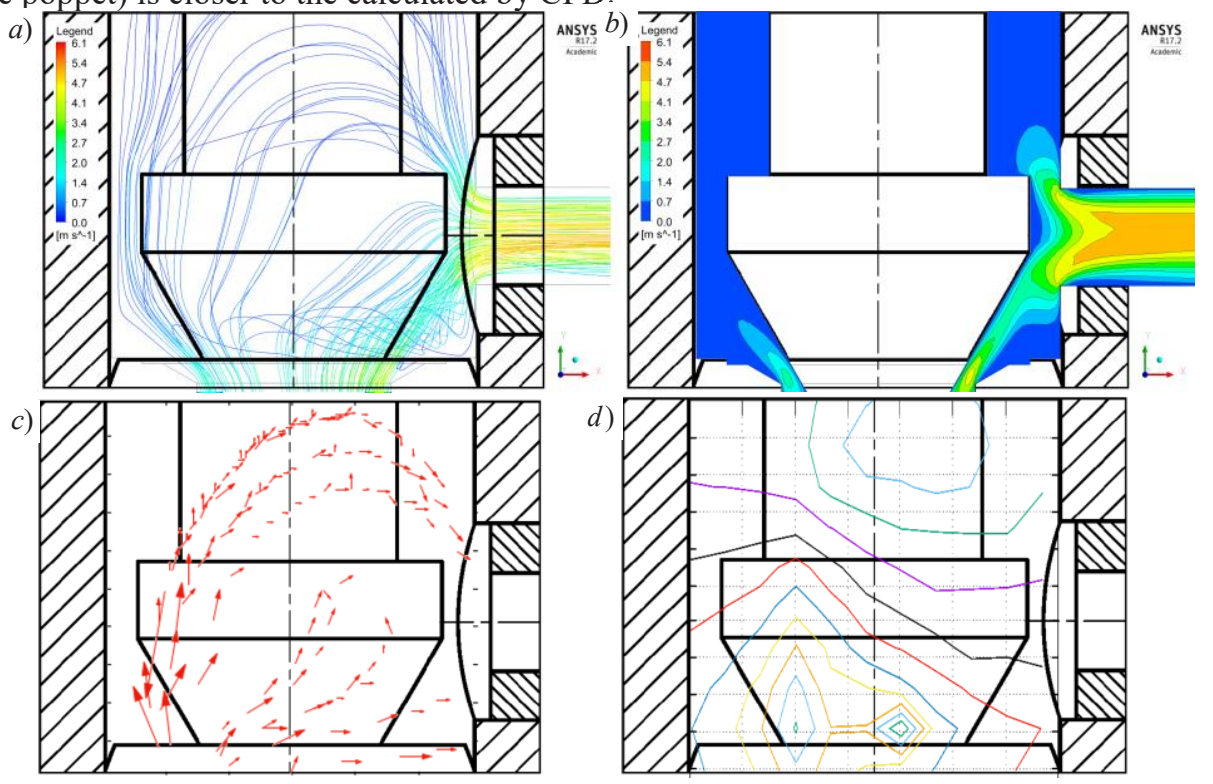

Fig. 4. Sample results of experimental measurements and numerical simulations of fluid flow through the valve with the conical poppet ( $h=3 \mathrm{~mm}, Q=10 \mathrm{dm}^{3} / \mathrm{min}$ ): a) stream lines (CFD), b) velocity field (CFD), c) selected stream lines (experimental), d) mean velocity field (experimental).

\section{Conclusion}

The analysis of flow phenomena with the PIV method proposed in the article is helpful in verifying the results of CFD simulations. Air bubbles at low pressure $\left(p_{1}=1.0 \mathrm{MPa}\right)$ enable to find the fluid flow in the channels and chambers of the hydraulic valve. The PIV method confirms the results obtained in numerical studies in a qualitative and quantitative way.

The resolution (800x600 px) and the frequency (500 to $2000 \mathrm{fps}$ ) are high enough to analyze the fluid velocity up to $v_{\max }=7 \mathrm{~m} / \mathrm{s}$. The body of PMMA is transparent and does not distort the view in the internal chambers. The light of $1000 \mathrm{~W}$ in total power with an additional reflecting plate arranged on the rear wall of the valve body allowed us to record images of the aperture $\mathrm{f} / 2.8$ with the exposure time $t_{\text {exp }}=400 \mu \mathrm{s}$.

Closing elements made with FDM worked properly up to the differential pressure $\Delta p=0.1 \mathrm{MPa}$. Conical poppet kept tightness in a fully closed position, although we observed small changes on the side surface at the end of the tests. 
The FDM method can be used to make closing elements with complex shapes. A limitation of this method is the accuracy which depends on the hardware (3D printers). PLA is too soft material to cooperate with the steel seats. Long-term operating of the poppets made of PLA can lead to loss of tightness in the poppet-seat connection.

Further research will be conducted in order to prepare the closing elements with other shapes. We will change the shape of the valve chamber and the flow paths as well as places of stud-ends. It is planned to print poppets of other materials, like acrylonitrile butadiene styrene (ABS) and to use another additive method, like Selective Laser Sintering (SLS) or Selective Laser Melting (SLM). Automatic processing of images obtained from the highspeed camera will be developed as well.

Calculations have been carried out using resources provided by Wroclaw Centre for Networking and Supercomputing (http://wcss.pl), grant No. 363.

\section{References}

[1] J. Stryczek, M. Banas, J. Krawczyk, Procedia Engineering, 176, 600-609 (2017)

[2] J. Stryczek, S. Bednarczyk, K. Biernacki, Arch. Civ. Mech. Eng., 14, 391-397, (2014)

[3] J. Krawczyk, J. Stryczek, Proceedings Of The 9th FPNI Ph.D Symposium On Fluid Power, 2016, (2017)

[4] L. Marciniak, M. Banas, J. Stryczek, Proceedings Of The 9th FPNI Ph.D Symposium On Fluid Power, 2016, (2017)

[5] P. Stryczek, F. Przystupa, M. Banas, Proceedings Of The 9th FPNI Ph.D Symposium On Fluid Power, 2016, (2017)

[6] A. Milecki, D. Rybarczyk, Stroj. Vestn.-J. Mech. E., 61 (9), 517-522, (2015)

[7] PJ. Gamez-Montero, P. Antoniak, R. Castilla, et al., Energies, 10, 1458, (2017)

[8] L. Rodionov, P. Rekadze, Procedia Engineering, 176, 636-644, (2017)

[9] A. Milecki, D. Sedziak, J. Intel. Mat. Syst. Str., 16(6), 501-510, (2005)

[10]P. Śliwiński, Pol. Marit. Res., 95, 58-67, (2017)

[11] J. Pobędza, A. Sobczyk, Key Engineering Materials, 542, 143-155, (2013)

[12]I. Gibson, D. Rosen, B. Stucker, Additive Manufacturing Technologies, SpringerVerlag New York, (2015)

[13] M. Terner, JWJ, 33(6), 1-5, (2015)

[14] Y. Huang, MC Leu, J. Mazumder, et al., ASME. J. Manuf. Sci. Eng., 137(1):014001, (2015).

[15] S.S. Fernández, M.M. Jiménez, J.J. Porras, et al., ASME. J. Mech., 138(2):024501, (2015).

[16] J. Stryczek, S. Bednarczyk, K. Biernacki, Arch. Civ. Mech. Eng., 14(4), 647-660, (2014)

[17] M. Taufik, K.J. Prashant, Surf. Topogr.: Metrol. Prop., 5:045003, (2017)

[18] S. Discetti, F. Coletti, Meas. Sci. Technol., 29:042001, (2018)

[19] J. Stryczek, P. Antoniak, O. Jakhno, et al., Arch. Civ. Mech. Eng., 1, 95-108, (2015)

[20]F. Gori, I. Petracci, M. Angelino, Int. J. Heat Fluid Fl., 44, 764-775, (2013)

[21] K. G. Dobrosel'skii, Journal of Engineering Physics and Thermophysics, 89(3), 695701, (2016)

[22]I. Murgan, F. Bunea, G.D. Ciocan, Flow Meas. Instrum., 54, 224-235, (2017). 